\title{
Organizational Stressors and Job Stress Among Malaysian Managers: The Moderating Role of Personality Traits
}

\author{
Kumaresan V. Sathasivam \\ School of Medicine, University Malaysia Sabah, Malaysia \\ Dr. Mohd Dahlan Hj. A. Malek \\ School of Psychology and Social Work, University Malaysia Sabah, Malaysia \\ Prof. Dr. Ahmad Faris Abdullah \\ School of Medicine, University Malaysia Sabah, Malaysia
}

Received: February 19, 2015 Accepted: May 7, 2015 Published: May 8, 2015

doi:10.5296/ijsw.v2i1.7338 URL: http://dx.doi.org/10.5296/ijsw.v2i1.7338

\begin{abstract}
Job stress is vastly present in today's organizations, and the costs of these phenomena cut across all levels of society. In recent years, researchers considering job stress in the workplace have made great strides in understanding several aspects of the stress phenomenon in the field of organizational behavior. Thus, it becomes more important that the individual variables of these job stresses are well explored and directly linked to individuals experiencing this situation, in order to ensure the right stressors are well understood and other moderating functions are studied, like the personality variables. This research presents an integration of past research and theory that models the relationship of organizational stressors like conflict, work overload, unfavorable work condition, and the moderating role of personality traits among managers. The scope of this study is limited to managerial positions in electronics firms in Malaysia. A set of demographic factors like gender, marital status and educational background, are also studied as influencing factors to job stress. The final framework in this study includes the organizational stressors as the independent variable and job stress as the dependent variable, with the personality traits moderating that relationship. A proportional sampling plan will be done to cover the surveys to be covering all major locations of electronics firms in Malaysia. Theoretical and managerial implications of the
\end{abstract}


study will be discussed in details. The implication of the study would be extremely beneficial for electronics organizations in not only identifying the organizational sources of job stress, but also to understand the personality behaviors of their management staffs and how that related to job stress. Organizational stressors play a big role in the study, in which understanding its influence to job stress and how to manage and cope would enable the leadership team in the electronics organizations to be able to handle job stress more efficiently.

Keywords: Job stress, Personality traits, Organizational stressors, Conflict, Work overload, Unfavorable work condition, Neuroticism and extraversion

\section{Introduction}

Today's managers face many challenges in the highly competitive working environments, characterized by lack of time, more uncontrollable factors, background distractions, lack of space, general uncertainty, and more administrative tasks that has resulted in job stress. In short, managerial work in organizations in exposed to highly stressful environments. Job stress is stress involving work. Job stress in the workplace appears to be a wide spread cross-cultural phenomenon. Most of the research work on stress has focused on basic elements, namely (a) antecedents of stress, (b) mediators of stress and (c) outcomes of stress (Jerusalem, 1993, as cited in Deary \& Blenkin, 1996). Depending on the subject's characteristic coping response, potential stressors may result in different outcomes in terms of physical and psychological disturbances (Endler \& Parker, 1990a, as cited in Deary \& Blenkin, 1996). In the case of personality, the dimension of neuroticism, one of the five personality traits, is thought to be an influential antecedent in human stress process (Deary \& Matthews, 1993).

Deary and Matthews (1993) states that in the case of personality dimensions, there has been a recently developing consensus as to the main dimensions of human temperamental variation, and the dimension of Neuroticism is thought to be an influential antecedent in the human stress process. Other concepts, such as coping styles and strategies, are currently undergoing a process of validation that involves criticism of earlier measurement instruments and the development of more adequate tools to measure ways of coping (Deary \& Matthews, 1993). Some critical attentions must be addressed to the outcome variables of stress models, which are often self-report measures of mental or physical ill health, or other aspects of negative well-being. Watson and Pennebaker (1989) study indicates it has been demonstrated that much of the variance in such self-reports may be captured by a general tendency towards negative reporting, called 'negative affectivity', which is similar to neuroticism personality trait. For stress models this has the important implication that outcome variables might reflect personality variance rather than objectively true stress outcomes.

In many countries, employers have a legal responsibility to recognize and deal with stress in the workplace so that employees do not become physically or mentally ill. It is important to tackle the causes of stress in the workplace as stress at work can lead to problems for the individual, working relationships and the overall working environment. These issues may include lowered self-esteem and poor concentration skills for the employee. The employer 
may suffer from increasing customer complaints, staff turnover and days lost to sickness. Managing stress in the workplace is therefore an essential part of both individual and corporate responsibility.

\subsection{Problem Statement}

Stress is a state that occurs when people are faced with events they perceive as endangering their physical or psychological well-being, and are unsure of their ability to deal with these events (Cook \& Hunsaker, 2001). Sources of stress are called stressors. Stressors, based on most studies include variables like environment, individual and organization (Matteson \& Ivancevich, 1999). For the past decade, the manufacturing sector has been undergoing constant technological development (Jestin \& Gampel, 2002). This is inevitably led to high pressure and job stress among managers in the work environment. Above all, the recent economic slowdown in the global economy has a significant effect on the local and multinational firms involving thousands of managers in the country. Many different job stressors contribute to job stress problems among these managers. Stressors prominently related to the organization itself, include conflict, work overload, unfavorable work conditions, and so forth. The other key stressor relates to individual variables like personality traits, personal problems and demographic factors and others. With the presence of job stress in the current world unavoidable, the big question is, whether the managers are aware of the impact of these organizational stressors and adapt to this challenges, as well as the influence of personality traits of the managers to their own well-being.

\section{Literature Review and Theoretical Framework}

\subsection{Job Stress Among Managers}

In no other segment of society has the interest in stress become more pronounced than in the business community. Corporate managers at all levels and of varied management styles are attempting to cope with problems resulting from stress at the workplace. Business and industry recognize stress as a reason for low productivity and high rates of absenteeism (Kahler, 1987) as well as high health care costs (Pelletier, 1984, as cited in Kahler, 1987). Medical and other studies have linked job-related stress to causes of coronary heart disease and stroke (Kahler, 1987). Executives, young and old, have been dropping out, switching professions or becoming ill (Kahler, 1987).

Managers cannot ignore the stress of their employees and it is in management's own self-interest to find ways to reduce it. However, stress is subjective, and people react to it in different ways. According to Szilagyi and Wallance (1990), as cited in Suzanne et al. (1998), some people adapt themselves to stress while others tolerate or avoid it. Similarly, some individuals go to pieces at the first sign of stress while other seems to thrive on it. Suzanne et al. (1998) postulates that much of a person's reaction to stress depends on the situation and their skills in prevention and reduction. According to Clarke and Watson (1991), managers have the highest level of stress simply because they are in the middle of the organization hierarchy, which can cause a great deal of conflict. Evidence suggests that the forms and intensity of stress are different depending on an individual's position within the organization. 
Supervisory and middle managers who have fewer opportunities to delegate often manifest more symptoms of stress than top executives (Kahler, 1987).

\subsection{Organizational Stressors and Job Stress}

Stress can be caused by environmental, individual and organizational variables (Matteson \&Ivancevich, 1999; Cook \& Hunsaker, 2001). These factors have been found to originate from both outside and inside the organization, from groups that employees interact with and from employees themselves. The phenomenal rate of social and technical changes has made a great impact on people's lifestyles, and this carried over to their job (Matteson \& Ivancevich, 1999). Organization variables as stress antecedents have been previously studied by researchers (Greenhaus \& Beutell, 1985). They found that work schedule, work environment and work orientation may all produce pressure for the individual to participate aggressively in their work role. This research will identify key organizational variables namely conflict, overload, and unfavorable work environment.

When the individual is exposed to stressors constantly, day after day, he or she might experience stress. Stress can be expressed in a variety of ways; one may be the way in which risk is perceived (Fiesel, 2006). These factors were chosen because they directly affect the perceptions or attitudes of a worker and organization. Job stress exists in many aspects of work, some study have established the personnel stress that delivery drivers experience by examining the job stressors and then determine if there is a link between job stress and how work risk is perceived (Chen et al., 1995, as cited in Fiesel, 2006).

\subsection{Personality Traits and Job Stress}

For the past decades, the potential impact of individual dispositions and preferences on workplace behavior and effectiveness has reemerged as one of the more significant research topics from general social psychological perspective (Goldberg, 1993; Snyder \& Ickes, 1985). Deary and Blenkin (1996) developed a transactional model of stress that reported job stress as a product of personality traits. Their study concluded that personality traits, particularly neuroticism, affect job stress. Recent researches have been found to be related to many organizational variables such as workload, role conflict or lack of autonomy and job strains like job dissatisfaction, work anxiety and somatic symptoms (Brief, et al., 1988; Watson, et al., 1986 as cited in Roberts et al., 1997). Spector (1992) argued that personal characteristics, for example, personality traits, gender, age and culture/ethnicity are important antecedents to job stress. On the other hand, personality traits like a predisposition have a positive effect on job stress and a negative effect on job satisfaction (Spector, 1992).

Over the past forty years, theories and researchers on personality have slowly converged on five board factors that appear to explain a majority of variance in work behaviors (John \& Srivastava, 1999). These five elements are neuroticism, extroversion, openness, agreeableness and conscientiousness and have been labeled as the 'Big Five'. These 'Big Five' factors represent orthogonal clusters of inter correlated behaviors (McCrae and Costa, 1999) that are expressive or stylistic in nature and have emerged robustly in empirical evidence across participants, raters, instruments and data sources (John \& Srivastava, 1999). 


\section{Macrothink}

International Journal of Social Work

ISSN 2332-7278

2015, Vol. 2, No. 1

Personality, defined as an individual's consistent patterns of thoughts, emotion and behavior, influences the selection and self-selection into jobs (Templer, 2011).

\subsection{Theoretical Framework and Hypotheses}

The conceptual framework for this study, as shown in Figure 1 is based on Karasek (1979) demand control model of job stress, Lazarus and Folkman (1984) theory of stress and evidence from the job-stress literature. Personality traits moderate the relationship between organizational variables and job stress. The aim of this study is to determine the relationship between organizational variables (Davies, et al., 2000) and personality traits (McCrae \& Costa, 1992) against job stress. The personality traits will be the moderating variable to the dependent variable, namely, job stress, with organizational stressors being the independent variable.

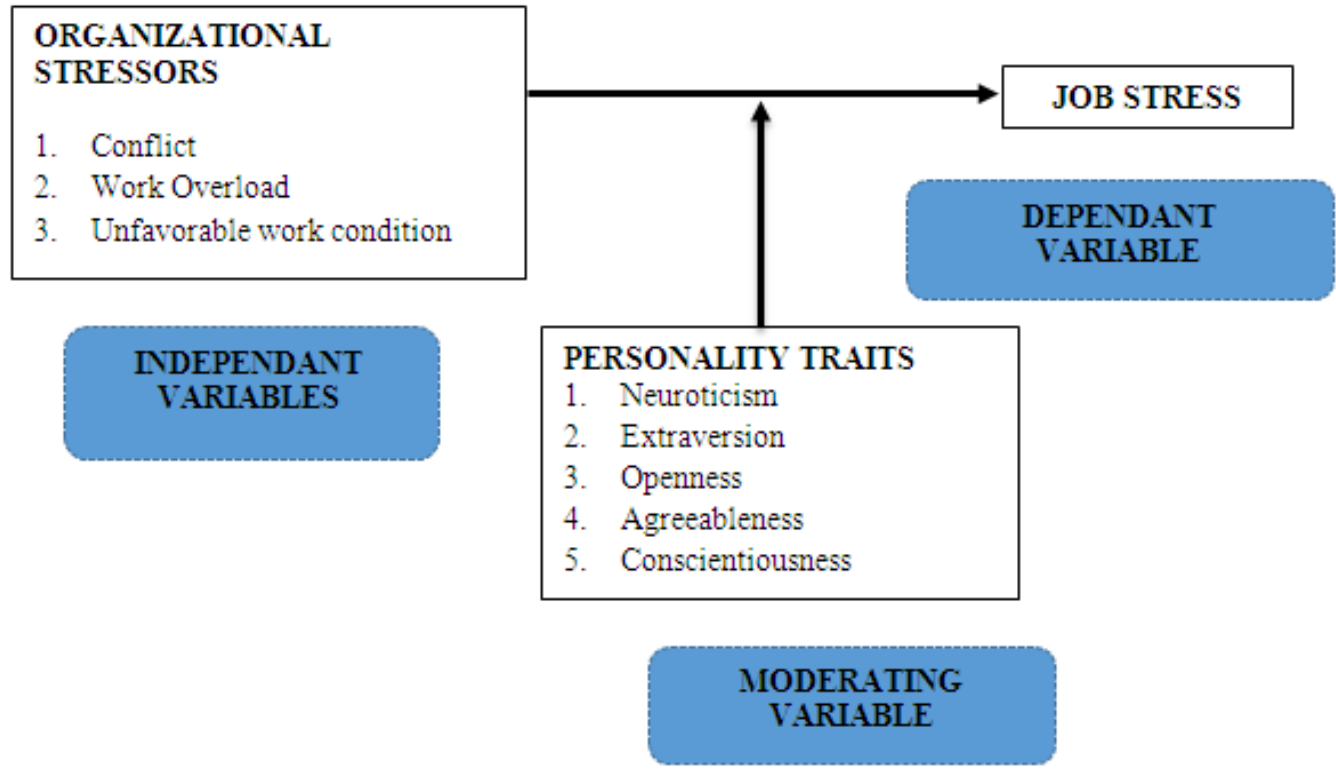

Figure 1. Theoretical Framework for this research

The hypotheses for the present study will be relating to test the influence of organizational stressors and personality traits to job stress. Davie et al. (2000) and McCrae and Costa (1992) have tested this case in previous researches. The hypotheses developed for the study are as shown below.

H1: Organizational variables influence job stress.

H1.1: Conflict has a positive relationship with job stress

H1.2: Overload has a positive relationship with job stress

H1.3: Unfavorable work conditions has a positive relationship with job stress 
$\mathrm{H} 2$ : Personality variables influence job stress

H2.1: Neuroticism has a positive relationship with job stress

H2.2: Extraversion has a positive relationship with job stress

H2.3: Openness has a positive relationship with job stress

H2.4: Agreeableness has a positive relationship with job stress

H2.5: Conscientiousness has a positive relationship with job stress

\section{Methods}

\subsection{Respondents}

This research is encompassed by a study using 400 managers from random electronics firms in Malaysia. The questionnaires were given in a hard-copy format and a time study was conducted. The purpose of this research is to investigate the relationship between coping methods and job stress. The nature of this study is correlational as it attempts to analyze the relationship between job stress and the coping variables. This is a field study and no artificial setting was created as it examines manager's coping styles towards job stress in their natural work environment. Each individual manager represents the unit of analysis in this study.

\subsection{Research Design}

The Sample - The study will cover electronics firms in Malaysia. There are huge numbers of factories involved in the electronics sector of the manufacturing industry in Malaysia that is located in various industrial zones throughout the country. In this research, electronics firms/factories were randomly selected based on a proportion sampling plan, based on the weighted percentage of the distributions of these electronics firms by states. This selection provided homogeneity in terms of electronics industry, yet it offered diversities in organization culture, which were dependent on the firm's country of origin. The Sampling Method - The first level sampling involves proportional study on the electronics firms' population in Malaysia. This data is obtained from the Malaysian Industrial Development Authority (MIDA), Latest Update 2009. The second level sampling involves identifying the number of firms located in these key industrial areas in Malaysia, proportion to the density of the electronics firms. The third level sampling involves the population of managers from the randomly selected firms.

\subsection{Variables and Measurement}

This section discusses the variables used in this research plus the measures for these variables respectively. All instruments were previously used from published literature (Davis, et al., 2000; McCrae \& Costa, 1992). The survey measurement scale utilizes a 5-point Likert response format for job stress measure, organizational variables and personality traits.

Job Stress Variable - job stress variable will perform a function of dependent variable to the antecedent variable (organizational sources of stress and personality variables). Job stress will be measured using a screening inventory which helps indicate one's levels of job stress 
(Davis et al., 2000).

Organizational Variables - Organizational variables include conflict, work overload and unfavorable work conditions. These variables will be measured using a structured questionnaire designed by Davis et al. (2000).

Personality Variables - Dimensions of personality will be accessed using the NEO Five Factor Inventory (Costa \& McCrae, 1992) that measures the following aspects of personality traits, namely, Neuroticism, Extraversion, Openness, Agreeableness and Conscientiousness. Given the fact that demographical factors may influence job stress, personal variables like gender, age, salary range, length of working years, educational status, marital status and job satisfaction will be statistically controlled.

\subsection{Methods of Analysis}

Job stress can be directly influenced by personal and external factors (Matteson \& Ivancevich, 1999), like personality trait and organizational stressors. To test all the hypotheses of the study, hierarchical regression will be done to determine the relationship between the job stress and the coping variables, statistically controlling the demographic variables. Examination on multicollinearity and its effects will also be done to further validate the regression results. The two part process (condition indices and the decomposition of the coefficient variance) will be done and comparisons will be made with the conclusions drawn from the variance inflation factor (VIF) and tolerance values. The condition indices and VIF not exceeding threshold value of 10 will be used (Ndubisi et al., 2001). A threshold of 3 standard deviation will be used to identify outliers. The model summary and ANOVA tests was also performed to check the $\mathrm{R}^{2}$ and $\mathrm{F}$ values to test whether the variables used in this study was sufficient and valid, plus utilization of these variables to measure job stress fits in the multivariate model.

\subsection{Mixed Model Approach}

In this study, mixed model approach was experimented (Tashakkori \& Teddlie, 2003), a sample of 25 managers out of the 40 during a pilot study was used for a qualitative study. In this session, a face to face setup was done, where a short presentation on the importance of the study for managers and the future of the electronics world was shared, as well as the implication of job stress and coping methods. A set of informal questions like the key types of organizational variables causing job stress; how organizations currently address job stress; the knowledge and actions that current companies have in addressing job stress and whether coping methods are well understood and the need to invest in understanding the best coping methods for management productivity, was all dialogued.

\section{Results and Analysis}

\subsection{Validity of the Instruments}

In the present study, data collected from different segments of the electronic industry in order to find out the influence of coping methods and individual factors on job stress. Content validity of the instrument was carried out through a Delphi technique by interviewing the first 
line managers, regional managers and some senior managers working in both domestic and multinational electronic companies at Malaysia. A total of 400 valid surveys was collected and analyzed, out of a total of 700 surveys sent. A socio demographic profiling was done from all the respondents that would analyze the breakdown by gender, age, salary range, length of working experience and educational status, marital status, as shown in Table 1.

Table 1. Overall Summary of Demographic profile of the respondents by frequency and percentage

\begin{tabular}{|c|c|c|c|}
\hline Factors & Variables & Frequency & Percent \\
\hline \multirow[t]{3}{*}{ Gender } & Male & 179 & 44.8 \\
\hline & Female & 221 & 55.2 \\
\hline & Total & 400 & 100.0 \\
\hline \multirow{6}{*}{ Age } & Less than 30 years & 3 & 0.8 \\
\hline & $30-35$ years & 123 & 30.8 \\
\hline & $35-40$ years & 154 & 38.5 \\
\hline & $40-45$ years & 102 & 25.5 \\
\hline & Above 45 years & 18 & 4.5 \\
\hline & Total & 400 & 100.0 \\
\hline \multirow{6}{*}{ Salary Range } & Below RM 5000 & 68 & 17.0 \\
\hline & RM 5000 - RM 10000 & 170 & 42.5 \\
\hline & RM 10000 - RM 15000 & 97 & 24.3 \\
\hline & RM 15000 - RM 20000 & 65 & 16.3 \\
\hline & Above 20000 & 0 & 0.0 \\
\hline & Total & 400 & 100.0 \\
\hline \multirow{6}{*}{$\begin{array}{c}\text { Working } \\
\text { Experience }\end{array}$} & Less than 1 year & 0 & 0.0 \\
\hline & 1 year -5 years & 25 & 6.3 \\
\hline & 5 years -10 years & 227 & 56.8 \\
\hline & 10 years -15 years & 115 & 28.8 \\
\hline & More than 15 years & 33 & 8.3 \\
\hline & Total & 400 & 100.0 \\
\hline \multirow{5}{*}{$\begin{array}{l}\text { Educational } \\
\text { Background }\end{array}$} & Diploma/Advanced Diploma & 4 & 1.0 \\
\hline & Bachelor's Degree & 251 & 62.8 \\
\hline & Master's Degree & 143 & 35.8 \\
\hline & $\mathrm{PhD} /$ Doctorate & 2 & 0.5 \\
\hline & Total & 400 & 100.0 \\
\hline \multirow{4}{*}{ Marital Status } & Single & 119 & 29.8 \\
\hline & Married & 261 & 65.2 \\
\hline & Separated/Divorced & 20 & 5.0 \\
\hline & Total & 400 & 100.0 \\
\hline \multirow[t]{3}{*}{ Job Satisfaction } & Yes & 320 & 80.0 \\
\hline & No & 80 & 20.0 \\
\hline & Total & 400 & 100.0 \\
\hline
\end{tabular}

Among the 400 respondents, $44.8 \%$ of them were male and $55.2 \%$ were female. In terms of 
marital status, $65.2 \%$ of them were married managers, while $29.8 \%$ single. Educational status showed heavier number of managers currently with a bachelor's degree at $62.8 \%$, while $35.8 \%$ of them were master's degree holders. Small population with either diploma/advanced diploma or PhD. at $1.5 \%$. Majority of the managers surveyed had a working experience of $5-10$ years at $56.8 \%$, followed by $10-15$ years at $28.8 \%$. Salary range showed most managers earning between RM5000-RM10000 at 42.5\%, while $24 \%$ of them earned between RM10000-RM15000. Biggest age group was between 35-40 years old, at 38.5\%, followed by $30-35$ years old at $30.8 \%$ and $40-45$ years old at $25.5 \%$. Through simple random and weighted sampling, data was collected from the managers from the electronics industries, from major industrial states in Malaysia. Descriptive statistics for mean and standard deviation is shown in Table 2.

Table 2. Descriptive Statistics for Organizational stressors, personality traits and job stress variables

\begin{tabular}{lccc}
\hline & Descriptive Statistics & & \\
\hline & $\mathrm{N}$ & Mean & Std. Deviation \\
\hline Conflict & 400 & 14.350 & 4.300 \\
\hline Work overload & 400 & 16.108 & 3.562 \\
\hline Unfavorable work condition & 400 & 12.800 & 2.604 \\
\hline Cognitive & 400 & 25.550 & 4.343 \\
\hline Social & 400 & 37.548 & 4.930 \\
\hline Openness & 400 & 49.035 & 4.572 \\
\hline Spiritual/Philosophical & 400 & 33.743 & 3.851 \\
\hline Physical & 400 & 33.283 & 3.670 \\
\hline Job stress & 400 & 52.703 & 11.646 \\
\hline Neuroticism & 400 & 34.013 & 4.031 \\
\hline Extraversion & 400 & 39.800 & 4.145 \\
\hline Openness & 400 & 39.850 & 3.100 \\
\hline Agreeableness & 400 & 39.215 & 2.993 \\
\hline Conscientiousness & 400 & 40.873 & 2.796 \\
\hline
\end{tabular}

Reliability and validity of the instruments were carried out for all the independent, mediating and dependent variables. Cronbach's Alpha value for all variables (coping variables and job stress) all scored between 0.6-0.9, indicating the instrument had strong to acceptable internal consistency of reliability (Sekaran, 2000). Construct validity test was also done to determine the validity of every questions in the instrument used. All this is summarized in Table 3 as shown below. 
Table 3. Reliability tests (Cronbach's Alpha value) for all variables

\begin{tabular}{llcc}
\hline Sl. no & Variables & Cronbach's Alpha value & No. of items \\
\hline $\mathbf{1}$ & Job stress & 0.918 & 20 \\
$\mathbf{2}$ & Conflict & 0.839 & 05 \\
$\mathbf{3}$ & Work Overload & 0.737 & 05 \\
$\mathbf{4}$ & Unfavorable work condition & 0.682 & 05 \\
$\mathbf{5}$ & Neuroticism & 0.669 & 12 \\
$\mathbf{6}$ & Extraversion & 0.670 & 12 \\
$\mathbf{7}$ & Openness & 0.643 & 12 \\
$\mathbf{8}$ & Agreeableness & 0.685 & 12 \\
$\mathbf{9}$ & Conscientiousness & 0.609 & 12 \\
\hline
\end{tabular}

Model summary and coefficient of ANOVA testing for coping methods to job stress $\left(\mathrm{R}^{2}=\right.$ $71.1 \% ; F=120.154)$, indicating the variables used in this study was sufficient and valid, plus utilization of these variables to measure job stress fits in the multivariate model. Besides the theoretical framework being supported by previous researches (Karasek, 1979; Lazarus \& Folkman, 1984), the qualitative study adopted during the pilot study that covered presentations, interviews and personal dialogues with sampled managers, had a huge impact to the healthy $\mathrm{R}^{2}$ and $\mathrm{F}$ numbers given by the model summary and ANOVA tests, as shown in Table 4 below.

Table 4. Model Summary and Coefficient of determination of ANOVA for coping variable

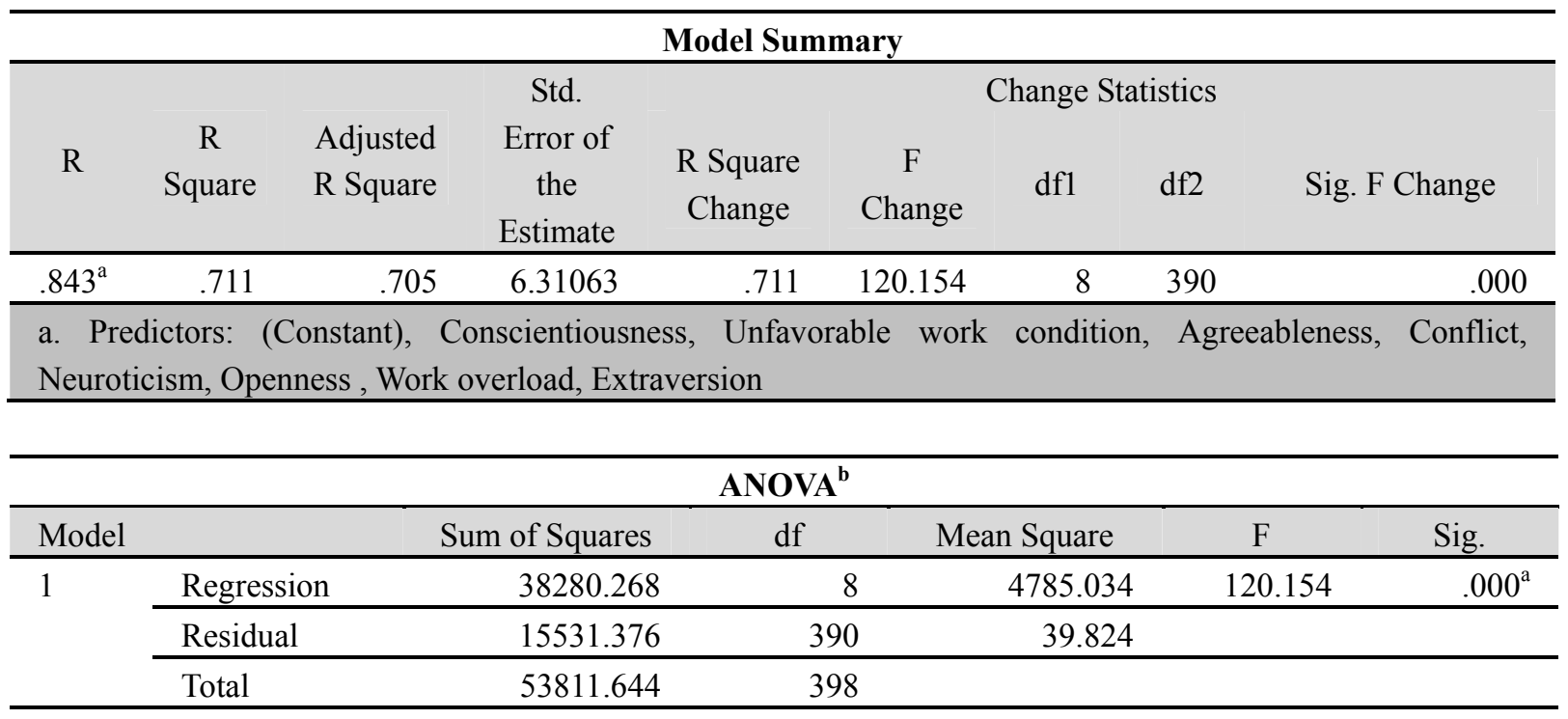

a. Predictors: (Constant), Conscientiousness, Unfavorable work condition, Agreeableness, Conflict, Neuroticism, Openness, Work overload, Extraversion b. Dependent Variable: Job stress

During the pilot study on 40 respondents, 25 of them was subjected to a qualitative study and was interviewed in relation to their job satisfaction, job stress awareness and actions taken by 
their employers or individuals on managing those stressful situations. Almost all of them, in summary, was satisfied with their managerial job, and supported the three big stressors in their work environment (conflict, work overload and unfavorable work condition) that would cause job stress at all levels. Interesting finding, was most of them were not aware of the personality traits that can be associated with the individual yet agreed that behaviors and believes would determine how a manager would perceive and manage job stress.

\subsection{Regression Analysis on Coping Methods}

Regression weights of all coping methods against the constant variable, job stress. The results are as shown in Table 5 below.

Table 5. Regression weights of all organizational, personality variables and job stress

\begin{tabular}{|c|c|c|c|c|c|c|}
\hline \multicolumn{2}{|r|}{ Model } & \multicolumn{2}{|c|}{ Unstandardized Coefficients } & \multirow{2}{*}{$\begin{array}{c}\text { Standardized } \\
\text { Coefficients }\end{array}$} & \multirow[t]{2}{*}{$\mathrm{t}$} & \multirow[t]{2}{*}{ Sig. } \\
\hline & & $\mathrm{B}$ & Std. Error & & & \\
\hline \multirow[t]{9}{*}{1} & (Constant) & 23.256 & 9.900 & & 2.349 & .019 \\
\hline & Neuroticism & 2.432 & .099 & .150 & 4.360 & .000 \\
\hline & Extraversion & -1.924 & .149 & -.330 & -6.212 & .000 \\
\hline & Openness & .544 & .145 & .145 & 3.754 & .000 \\
\hline & Agreeableness & .751 & .147 & .193 & 5.095 & .000 \\
\hline & Conscientiousness & -.959 & .174 & -.231 & -5.504 & .000 \\
\hline & Conflict & 1.852 & .078 & .686 & 23.644 & .000 \\
\hline & Work overload & .004 & .159 & .001 & .026 & .979 \\
\hline & $\begin{array}{l}\text { Unfavorable work } \\
\text { condition }\end{array}$ & 1.011 & .142 & .225 & 7.120 & .000 \\
\hline
\end{tabular}

$Y=23.256+2.432 X_{1}-1.924 X_{2}+0.544 X_{3}+0.751 X_{4}-0.959 X_{5}+1.852 X_{6}+0.004 X_{7}+1.011 X_{8}+C$

In the present study, out of eight variables tested, six variables, namely neuroticism, openness, agreeableness, conflict, and unfavorable work condition are significant at five percent level. However, extraversion and conscientiousness are negative in value, which implies that an increase in the job stress will result in reducing extraversion and conscientiousness. Work overload was not significant at $p=0.979$. The higher the $B$ value for unstandardized coefficients, the better contributors or larger magnitude these variables are for job stress. In this analysis, neuroticism was at $2.432(\mathrm{p}=0.000)$ and conflict at $1.852(\mathrm{p}=0.000)$, showing a strong significance at $95 \%$ level. Both of this variables will positively increase for an increase in job stress. While extraversion was at $-1.924(\mathrm{p}=0.000)$, would negatively increase in magnitude for an increase in job stress, also with a strong significance at $95 \%$ level. This finding is supported by previous researches that states job stress have high magnitude of influence by conflict (Hendrix, 1989, as cited in Roberts et al,. 1997), work environment (Quick et al., 1997), neuroticism (Watson \& Pennebaker, 1989; Birch \& Kamali, 2001) and negatively in relationship with extraversion (Birch \& Kamali, 2001; Attia, 2013). 


\section{Ml Macrothink}

\subsection{Hypotheses Testing}

Spearman correlation test has been carried out to test the framed hypothesis in the study. This method was used because both the dependent variable (job stress) and the coping methods are both in continuous (Likert's) scale (Jerome \& Arnold, 2003). The hypotheses (H1 and H2) that was developed in this study was to test the relationship between organizational variables and personality variables against job stress, as shown below. Table 6 shows the correlation analysis for the eight tested hypotheses.

Table 6. Spearman's Correlation for Organizational, personality variables and job stress (Hypotheses Testing)

\begin{tabular}{|c|c|c|c|c|c|c|}
\hline \multicolumn{7}{|l|}{ Correlations } \\
\hline & & & Conflict & $\begin{array}{l}\text { Work } \\
\text { overload }\end{array}$ & $\begin{array}{l}\text { Unfavorable } \\
\text { work condition }\end{array}$ & Job stress \\
\hline \multirow[t]{8}{*}{$\begin{array}{l}\text { Spearman' } \\
\text { s rho }\end{array}$} & \multirow[t]{2}{*}{ Conflict } & $\begin{array}{l}\text { Correlation } \\
\text { Coefficient }\end{array}$ & 1.000 & -0.048 & 0.286 & 0.717 \\
\hline & & Sig. (2-tailed) & - & 0.341 & 0.000 & 0.000 \\
\hline & \multirow[t]{2}{*}{ Work overload } & $\begin{array}{l}\text { Correlation } \\
\text { Coefficient }\end{array}$ & -0.048 & 1.000 & 0.317 & 0.052 \\
\hline & & Sig. (2-tailed) & 0.341 & & 0.000 & 0.298 \\
\hline & \multirow[t]{2}{*}{$\begin{array}{l}\text { Unfavorable } \\
\text { work condition }\end{array}$} & $\begin{array}{l}\text { Correlation } \\
\text { Coefficient }\end{array}$ & 0.286 & 0.317 & 1.000 & 0.698 \\
\hline & & Sig. (2-tailed) & 0.000 & 0.000 & & 0.000 \\
\hline & \multirow[t]{2}{*}{ Job stress } & $\begin{array}{l}\text { Correlation } \\
\text { Coefficient }\end{array}$ & 0.717 & 0.052 & 0.698 & 1.000 \\
\hline & & Sig. (2-tailed) & 0.000 & 0.298 & 0.000 & \\
\hline
\end{tabular}

\begin{tabular}{|c|c|c|c|c|c|c|c|}
\hline \multicolumn{8}{|l|}{ Correlations } \\
\hline \multicolumn{2}{|l|}{ Spearman's rho } & \multicolumn{6}{|c|}{ Job stress Neuroticism Extraversion Openness Agreeableness Conscientiousness } \\
\hline \multirow{2}{*}{ Job stress } & Correlation Coefficient & 1 & 0.745 & -0.617 & -0.062 & 0.074 & -0.179 \\
\hline & Sig. (2-tailed) & . & 0 & 0 & 0.217 & 0.139 & 0.318 \\
\hline \multirow{2}{*}{ Neuroticism } & Correlation Coefficient & 0.745 & 1 & 0.547 & -0.352 & 0.378 & 0.255 \\
\hline & Sig. (2-tailed) & 0 & & 0 & 0 & 0 & 0 \\
\hline \multirow{2}{*}{ Extraversion } & Correlation Coefficient & -0.617 & 0.547 & 1 & -0.159 & 0.646 & 0.541 \\
\hline & Sig. (2-tailed) & 0 & 0 & & 0.001 & 0 & 0 \\
\hline \multirow{2}{*}{ Openness } & Correlation Coefficient & -0.062 & -0.352 & -0.159 & 1 & -0.358 & 0.19 \\
\hline & Sig. (2-tailed) & 0.217 & 0 & 0.001 & . & 0 & 0 \\
\hline \multirow{2}{*}{ Agreeableness } & Correlation Coefficient & 0.074 & 0.378 & 0.646 & -0.358 & 1 & 0.201 \\
\hline & Sig. (2-tailed) & 0.139 & 0 & 0 & 0 & & 0 \\
\hline \multirow{2}{*}{ Conscientiousness } & Correlation Coefficient & -0.179 & 0.255 & 0.541 & 0.19 & 0.201 & 1 \\
\hline & Sig. (2-tailed) & 0.318 & 0 & 0 & 0 & 0 & . \\
\hline
\end{tabular}

H1.1 testing indicates, conflict have a strong correlation on job stress $(71.7 \%)$ at a 
significance of $p=0.000$, hence based on this, the alternate hypothesis is accepted and it is confirmed the conflict will positively influence job stress. This finding is further supported by studies in regards to the effect of individual's stress to role conflict have shown positive relationships to job stress (Hendrix, 1989, as cited in Roberts et al,. 1997). Role conflict has been found to exist when an individual has two or more role requirements that work against each other (Kahn et al., as cited in Rahim, 1996). As Cooper et al. (2001) stated that role conflict in particular would be associated with burnout.

H1.2 testing shows work overload have no correlations to job stress (5.2\%) at a significance of $p=0.298$, hence based on this, the alternate hypothesis is rejected and it is confirmed the work overload will not influence job stress. This results does not support various previous researches that indicates strong relationship of over loaded work to job stress (Karasek \& Theorell, 1990; Buckingham, 2004; Cooper et al. (2001) and Kumaresan, et al. (2004) did a similar research on a smaller scale of managers showed and supported this finding that work overload did not have any significance to job stress.

H1.3 testing resulted in unfavorable work condition have strong correlation $(69.8 \%)$ at a significance of $p=0.000$, hence based on this, the alternate hypothesis is accepted and it is confirmed the unfavorable work condition will positively influence job stress. This finding is well support by previous literatures (Fiesel, 2006), that found the unfavorable nature of work environment, has contributed to job stress.

H2.1 hypotheses testing showed that neuroticism have a strong correlation on job stress at $74.5 \%(p=0.000)$, hence based on this, the alternate hypothesis is accepted and it is confirmed the neuroticism will positively influence job stress. This finding is widely supported by previous researches. Deary \& Matthews (1993) suggested that the personality dimension of neuroticism is an influential antecedent in the human stress process. According to Deary \& Matthews (1993), neuroticism is found to have a positive correlation to job stress. Watson \& Pennebaker (1989) in their study found the neuroticism had a direct relationship with stress. Another study by Birch \& Kamali (2001) discovered that job stress and depression were positively correlated with neuroticism trait. An elevated neuroticism score points out that the person tends to have a nervous and irritable character, to be less able to control anxiety and to deal poorly with stress (Attia, 2013).

H2.2 test identified that extraversion have a strong correlation on job stress $(-61.7 \%)$ at a significance of $p=0.000$, hence based on this, the alternate hypothesis is rejected and it is confirmed the extraversion will negatively influence job stress. As found in previous studies, extraverted personality tend to be happier in their jobs and suffer lower levels of job stress (Attia, 2013). Birch \& Kamali (2001) concluded that extroversion dimension of personality had a negative relationship with job stress, anxiety and depression, that directly supports the finding in this study. Snyder \& Ickes (1985) suggested that an individual with extroversion tendencies learn to exhibit enthusiastic, energetic, and positive behaviors in setting where social approval or positive outcomes are likely to follow.

H2.3 test showed openness have a no correlation and significance on job stress at $6.2 \%$ $(p=0.217)$, hence based on this, the alternate hypothesis is rejected and it is confirmed the 
openness will not influence job stress. People with a high score in openness are more creative, more productive and efficient in art and science, and they tend to be less rules-constrained, thus will not be influenced to experience job stress (Attia, 2013). Innes \& Kitto (1989) assessed the relationship between personality characteristics that resulted in openness trait having no clear correlation to job stress.

H2.4 test showed agreeableness have a no correlation and significance on job stress at $7.4 \%$ $(p=0.139)$, hence based on this, the alternate hypothesis is rejected and it is confirmed the agreeableness will not influence job stress. Innes \& Kitto (1989) assessed the relationship between personality characteristics that resulted in agreeableness trait having no clear correlation to job stress. Graziano \& Eisenberg (1997) also supported this, and discovered that agreeableness trait had no relationship with job stress or even anxiety.

$\mathrm{H} 2.5$ test showed conscientiousness have a no correlation and significance on job stress at $17.9 \%(\mathrm{p}=0.318)$, hence based on this, the alternate hypothesis is rejected and it is confirmed the conscientiousness will not influence job stress. This finding is supported by a previous meta-analyses (Judge \& Ilies, 2002, as cited in Parks \& Guay, 2009) of relationships between personality and motivation, that indicated conscientiousness personality do experience lower job stress levels. Innes \& Kitto (1989) concluded there is no direct relationship between conscientiousness and job stress.

\section{Discussions}

\subsection{Major Findings}

Hypotheses 1 (H1) was tested based on the influence of organizational variables to job stress. Results showed that conflict and unfavorable work condition, both showed high significance at $95 \%$ level $(\mathrm{p}=0.000)$, through regression analysis, and a strong correlation to job stress, with conflict at $71.7 \%$ and unfavorable work condition at $69.8 \%$ correlation. Hypotheses 2 (H2) was tested based on the influence of personality variables to job stress. Results showed that neuroticism (positively) and extraversion (negatively) trait, both showed high significance at $95 \%$ level $(\mathrm{p}=0.000)$, through regression analysis, and a strong correlation to job stress, with neuroticism at $74.5 \%$ positively and extraversion at $61.7 \%$ correlation negatively. The remaining three other personality traits, namely, openness, agreeableness and conscientiousness, all show significance but not strong, based on results that was generated from the regression analysis, and do not have any correlation strength with job stress.

Conflict was found to be influencing managers in terms of their roles, responsibilities and expectations on datelines, which covers their work life as well as their personal life. Role conflict that was most commonly shared was having a couple of roles in their respective managerial position. For example, a manager can be the lead for his team within an organization that is running an operations business, and at the same time, he might also be involved in other programs, like at the site level or involved in cross collaborations to other organizations within the same company. Previous studies have widely researched the relationship between conflict and job stress. Rahim (1996) studied and proved the positive relationship between conflict and job stress, and subsequently found that the existence of role 
conflict when an individual has two or more role requirements that work against each other, thus resulting in job stress. Hendrix (1989), as cited in Roberts et al., (1997) also tested on effects of role conflicts to be positively associated to job stress.

Unfavorable work condition was also found to be a key stressor for electronic companies based managers. In interviews, the popular reasons for unfavorable work conditions were mainly on diversity and inclusion gaps. Diversity here in the Asian culture was more towards two domains, firstly, the gender diversity between male and female, and secondly, was on the ethnicity diversity, between various races in the electronics firms located in Malaysia. The other element that was closely connected to the unfavorable work place was favoritism. This in most recent years has become a big reason for creating a very unhealthy work environment, not only among managers, but among all layers of any organization. Quick et al. (1997) studied on job stress and its relationship with work conditions. The study revealed global competitions creates a very unfriendly work conditions and has significantly contributed to job stress among management staffs in most industries. Unfavorable work condition was found to be a key organizational stressor and would result in higher levels of depression and job stress (Holahan and Moos, 1983, as cited in Eugene, 1999). Economic events, globalizations and downsizings would result in job security fears among managers and this would directly relate to managers experiencing job stress due to the insecure work environment (Carayon, 1995).

Work overload had no significance to job stress among managers in the electronics industry. From the interviews, most managers felt that work load increase has just become a norm and part of their daily routine, in which could be the reason why work overload did not come out as a significant organizational stressor to job stress. Another assumption was that work overload kind of situations are not widely happening among the managers in the electronics industries. This triggers the believe that sudden requests of pulled in timelines or additional work load or unplanned job requests are becoming less of an issues probably because it's not happening in a large scale or managers have gotten a hang on how to handle such situations. Thus, this variable may not be viewed as an organizational stressor (Kumaresan, et al., 2004). Work overload is referred to when the employees' role expectations exceed the resources or time available to fulfill assigned responsibilities (Bacharach et al., 1991). This study also revealed that if an employee manages their work load effectively in terms of responsibilities and expectations, the influence of job stress would be less to none.

People with neuroticism traits are those experiences more negative emotions and who reports less satisfaction with life than most people (Costa \& McCrae, 1992). This group of people also portray emotional tendencies like anxiety, low self-esteem and tension. At this current trend in electronics industry in Malaysia, being in a fast paced environment where changes are inevitable, many managers do showcase this neuroticism trait, especially when they cannot manage and cope with changes and high demands of performance in this industry. Managers with neuroticism trait and its direct positive relationship with job stress have been widely studied and tested. Watson \& Pennebaker (1989) in their study found the neuroticism had a direct relationship with job stress. Deary \& Blenkin (1996) further tested and supported that job stress is a product of personality traits (especially neuroticism) and perceived 
workload. Birch \& Kamali (2001) discovered that job stress and depression were positively correlated with neuroticism trait.

Extraversion trait as tabled by McCrae and Costa (1999) is defined by characters that exhibit high intensity of interpersonal interaction. An individual with this trait would show case strong tendency of being sociable, active, talkative, person oriented, optimistic, fun-loving and affectionate. This study found managers in the electronics industry that has high extraversion personality was found to experience lower level of job stress, as the correlations were strong negatively. Managers that fall into this personality trait practice reaching out to others and having strong connections with the people in the environment. The strong negative relationship between extraversion and job stress is been previously researched and supported. Birch and Kamali (2001) concluded that extroversion dimension of personality had a negative relationship with job stress, anxiety and depression. Snyder and Ickes (1985) suggested that an individual with extroversion personality tend to be more enthusiastic, energetic, and portray positive behaviors in setting where social approval or positive outcomes are likely to follow, and one significant outcome is better adoption and management of job stress.

Openness, agreeableness and conscientiousness based traits in terms of their relationship to job stress was found to be less significant and no correlations. This is supported by a study by Innes and Kitto (1989), whom discovered that personality characteristics of openness, agreeableness and conscientiousness had no clear relationship with job stress.

\subsection{Implication and Contributions}

The implication of the study is divided from four difference perspective, namely, theoretical viewpoint, individual/managerial viewpoint, organizational viewpoint and economic viewpoint. Finally, how these viewpoints are summarized and how it can contribute back to the manager's personal well-being, the electronics organization and the nation would also be discussed. Job stress has become one of the key root-causes of poor performances of employees in any organizations (Cook \& Hunsaker, 2001). This study identifies the influence of organizational stressors and personality traits towards job stress among managers in the electronics industry in Malaysia. Theoretical viewpoint of this study reveals that personality traits do moderate job stress, with neuroticism trait showing a positive relationship to job stress while extraversion having a negative relationship. The remaining traits like openness, agreeableness and conscientiousness does not show a strong significance towards job stress.

Individual/managerial viewpoint is constructed based on how the importance of these findings and how it reflects individually to the manager. Beyond all, knowing the presence of organizational stressors is critical. Likewise knowing your personality trait, would benefit how managers would respond to job stress. This would allow managers to understand their personality traits and organizational stressors to job stress, thus ensuring their social, professional and family life are well balanced. From the organizational viewpoint, the whole model of understanding what causes job stress and how the job stress can be influenced by an individual's personality to result in highly productive managerial staffs will be very beneficial, for any organizations. In understanding, acknowledging and managing the stressors and personality traits to job stress would enable companies to promote more cognitive related 
activities like social events, team buildings, conferences, community of practices for common hobbies that would allow and enable managers to be in the environment that would best suit and promote their ability to manage with job stress effectively. Economic viewpoint is more from the benefits to the nation and the economy of the country, through the establishment of a better stress management process and system within the electronics firms. With the helm of every company's leadership for electronics sector being more composed, balanced work life and highly productive, it shapes well for growth in Malaysia for electronics industry in general.

Contributions in of this study would be timely, for the electronics industry being one of the nation's big economic drivers, is experiencing down-sizing and slow down, due to global economic situations. The findings on personality variables for managers with specific demographics will enable a better job stress management, which will be phenomenal for the productivity and the well-being of the individual manager and the continued success of the electronics firms. This will allow firms and companies to develop avenues to suit the rightful facilities and forums to address job stress for their employees. This would result in a more balanced managerial workforce in terms of work life effectiveness, which will result in highly motivated individuals, a happier society, highly productive organizations and a huge economy boost for the nation.

\subsection{Limitation of the Study}

From the methodology perspective, the sample size that was used in this study was 400, from various electronics firms around Malaysia. Key contributing states would include Pulau Pinang, Kuala Lumpur, Selangor and Johor. In view of that, a larger sample would provide a statistically firmer base to access the relationship between the independent variables and coping methods to job stress among managers in Malaysia. A larger sample size is preferred, to generalize the findings. Another key note is the study only targets the electronics industry in Malaysia, hence the results obtained from this study may not be applicable to other industries like textile, transportation, steel, chemicals, and government sectors and so forth.

From the managers' perspective as the key sample for this study, the key limitation related to job stress itself. In this context, job stress is defined as stress faced by managers at work place, where as in the actual fact, managers would experience stresses from other sources besides job, which would have a direct implication to their respective stress levels at work. These external factors were not investigated in this study. Physiological state of mind of the managers when they are answering the survey would play a big part in the outcome of the study. Finally from the environmental perspective, the country's economic conditions and stability plays a significant role in determining the manager's job stress in the electronics industry, especially when electronics are Malaysia's biggest contributor in terms of export based income. This external factor was not considered during the time of the study, and will have a significant impact to the levels of job stress among the managerial workforce. The other significant environmental difference that was not include in this study was the country of origin of the electronics firm. It is believed that the stress levels at work experienced by employees are different for different origins of the company, due to its internal culture. 


\section{Conclusion}

In summary, the study provided insight on the validity of the stress model using managers' sample in the electronics industry the Malaysia. The findings in this study suggest that the stress models developed by previous scholars like Karasek (1979), Lazarus and Folkman (1984) and Matteson and Ivancevich (1999), can be applied within the Malaysian context. This study as a whole concludes that job stress is widely presence among managers in the electronics industry in Malaysia. Conflict as an organizational stressor was very prevalent among managers to job stress for both genders. Managers having high neuroticism trait show cased higher experience to job stress, while extraversion trait had a negative relationship to job stress. It is with hope that the finding of this study will be useful for managers individually and organizations to understand the presence of job stress and possible methods that would enable managers to cope with job stress effectively.

\section{References}

Attia, N. (2013). Big Five personality factors and individual performance. Masters Dissertation. University of Quebec, Chicoutimi, 2013. http://dx.doi.org/10.1522/030585422

Bacharach, S., Bamberger, P., \& Conley, S. (1991). Work home conflict among nurses and engineers: Mediating the impact of role stress on burnout and satisfaction at work. Journal of Organizational Behavior, 12(1), 39-53. http://dx.doi.org/10.1002/job.4030120104

Birch, D. N., \& Kamali, F. (2001). Psychological stress, anxiety, depression, job satisfaction, and personality characteristics in pre-registration house officers, Postgraduate Medical Journal, 77(904), 109-121. http://dx.doi.org/10.1136/pmj.77.904.109

Carayon, P. (1995). Chronic Effect of Job Control, Supervisor Social Support, and Work Pressure on Office Worker Stress. In S. L. Sauter \& L. R. Murphy (Eds.). Organizational Risk Factors for Job Stress (pp. 357-370), Washington DC American Psychological Association. http://dx.doi.org/10.1037/10173-022

Clark, L. A., \& Watson, D. (1991). Tripartite model of anxiety and depression: Psychometric evidence and taxonomic implications. Journal of Abnormal Psychology, 100(12), 316-336. http://dx.doi.org/10.1037/0021-843X.100.3.316

Cook, C.W., \& Hunsaker, P. L. (2001). Management and Organizational Behavior (3rd Ed.), New York: McGraw Hill.

Cooper, C. L., Kirkaldy, B. D., \& Brown, J. (1994). A model of job stress and physical health: The role of individual differences. Personality and Individual Differences, 16, 653-655. http://dx.doi.org/10.1016/0191-8869(94)90194-5

Davis, M., Elizabeth, R. E., \& Matthew, M. (2000). The Relaxation and Stress Reduction Workbook. (5th Ed.). New Harbinger Publication, Inc., New York.

Deary, I. J., \& Blenkin, H. (1996). Models of job-related stress and personal achievement among consultant doctors. British Journal of Psychology, 87(1), 3-27. http://dx.doi.org/10.1111/j.2044-8295.1996.tb02574.x 
Deary, I. J. \& Matthews, G. (1993). Personality traits are alive and well. The Psychologist, 6(12), 299-311.

Eugene, J. W. (1999). The Impact of Work Resources on Job Stress among Correctional Treatment Staff. Journal of Addictions and Offender Counseling, 20(1), 26-34. http://dx.doi.org/10.1002/j.2161-1874.1999.tb00138.x

Fiesel, T. L. W. (2006). Job Satisfaction, Job Stress and Working Conditions and Their Relationship to Perception of Risk. Dissertation. The University of Wisconsin, Madison, 2006.

Goldberg, L. R. (1993). The Structure of Phenotypic Personality Traits. American Psychologist, 48(1), 26-34. http://dx.doi.org/10.1037/0003-066X.48.1.26

Graziano, W. G., \& Eisenberg, N. H. (1997). Agreeableness: A dimension of personality. Handbook of Personality Psychology (pp. 795-824), San Diego: Academic Press. http://dx.doi.org/10.1016/B978-012134645-4/50031-7

Greenhaus, J. H., \& Beutell, N. J. (1985). Sources of Conflict between Work and Family Roles. Academy of Management Review, 12(6), 120-128. http://dx.doi.org/10.2307/258214

Innes, J. M., \& Kitto, S. (1989). Neuroticism, self-consciousness, and coping strategies and occupational stress in high school teachers. Personality and Individual Differences, 10(2), 303-312. http://dx.doi.org/10.1016/0191-8869(89)90103-7

Jerome, M. L., \& Arnold, W. D. (2003). Research Design and Statistical Analysis (2nd Ed.). Lawrence Erlbaum. p. 508.

Jestin, W., \& Gampel. A. (2002). The Big Valley, Global Outlook. Toronto: McGraw Hill.

John, O. P., \& Srivastava, S. (1999). The Big Five-Trait taxonomy: History, measurement, and theoretical perspectives. In L. Pervin \& John (Eds.), Handbook of personality: Theory and Research (pp. 102-138). New York: Guilford.

Kahler, H. S. Jr. (1987). Stress management among corporate manager: A study of the relationship among management styles, management levels and coping behavior. Dissertation. Iowa State University, Ames, IA.

Karasek, R. A. (1979). Job demands, job decision latitude, and mental strain: Implications for job redesign. Administrative science quarterly, 24(2), 285-308. http://dx.doi.org/10.2307/2392498

Kumaresan, S. (2002). Antecedents and Outcomes of Job Stress: A Study among Managers in the Electronics Industry in Penang (pp. 59-69). MBA thesis, University Science Malaysia.,

Kumaresan, S., Nasurdin. M. A., \& Ramayah, T. (2004). Organizational and Personality Influence on Job Stress: The Case of Malaysian Managers. Malaysian Management Review, $39(2), 35-43$.

Lazarus, R. S., \& Folkman, S. (1984). Stress, Appraisal and Coping. New York, NY: 
Springer.

Malaysian Investment Development Authority (MIDA). (2013). Industries in Malaysia: Electrical and electronics industry.

Matteson, M. T., \& Ivancevich, J. M. (1999). Organizational Behavior and Management (5th Ed.), New York: McGraw Hill.

McCrae, R. R (Ed.). (1992). The Five-Factor Model: Issues and Applications. Journal of $\begin{array}{llll}\text { Personality } & \text { (Special } & \text { Issue), } & \text { 60(2), }\end{array}$ http://dx.doi.org/10.1111/j.1467-6494.1992.tb00970.x

McCrae, R. R., \& Costa, P. T., Jr. (1999). A Five-Factor Theory of personality. In L. A. Pervin \& O. P. John (Eds.), Handbook of personality: Theory and Research (pp. 102-153). New York: Guilford.

Ndunisi, N. O., Jantan, M., \& Ricardson, S. (2001). Is The Technology Acceptance Model Valid For Entrepreneurs? Model Testing and Examining Usage Determinants. Asian Academy of Management Journal, 6(2), 40-46.

Parks, L. \& Guay, R. P. (2009). Can Personal Values Predict Performance? Evidence in an Academic Setting. Applied Psychology: An International Review, 61(1), 149-173. http://dx.doi.org/10.1111/j.1464-0597.2011.00461.x

Quick, J. C., Quick, J. D., Nelson, D. L., \& Hurrell, J. J. (1997). Preventive Stress Management in Organizations. Washington, DC: American Psychological Association. http://dx.doi.org/10.1037/10238-000

Rahim, A. (1996). Stress, Strain, and Other Moderators: An Empirical Comparison of Entrepreneurs and Managers. Journal of Small Business Management, 34(1), 46-58.

Roberts, J. A., Lapidus, R. A., \& Chonko, L. B. (1997). Salesperson and Stress: The Moderating Role of Locus of Control on Work Stressors and Felt Stress. Journal of Marketing Theory and Practice, 5(3), 93-108.

Sekaran, U. (2000). Research Methods for Business. (3rd Ed.), New York: John Wiley \& Sons Inc.

Snyder, M. \& Ickes, S. W. (1985). Personality and social behavior. In G. Lindzey St E. Aronson (Eds.). The Handbook of Social Psychology, 3(2), 883-947.

Spector, P. E. (1992). A consideration of the validity and meaning of self-report measures of job conditions. International Review of Industrial and Organizational Psychology, 21(78), 123-151.

Suzanne, M. C., John, H. W, Jitendra, M. M., \& Steve, P. (1998). Stress and Stress Management. The S.A.M Advanced Management Journal, 60(3), 10-19.

Tashakkori, A., \& Teddlie, C. (2003). Handbook of Mixed Methods in Social \& Behavioral Research. SAGE Publications, 2003 - Social Science. 
Templer, K. J. (2011). Five-Factor Model of Personality and Job Satisfaction: The Importance of Agreeableness in a Tight and Collectivistic Asian Society. Applied Psychology: An International Review, 61(1), 114-129. http://dx.doi.org/10.1111/j.1464-0597.2011.00459.x

Watson, D., \& Pennebaker, J. W. (1989). Health complaints, stress, and distress: Exploring the central role of negative affectivity. Psychological Review, 96, 234-254. http://dx.doi.org/10.1037/0033-295X.96.2.234

\section{Copyright Disclaimer}

Copyright reserved by the author(s).

This article is an open-access article distributed under the terms and conditions of the Creative Commons Attribution license (http://creativecommons.org/licenses/by/3.0/). 